\title{
Analysis of the p16INK4 and TP53 Tumor Suppressor Genes in Bone Sarcoma Pediatric Patients
}

\author{
A. Patiño-García and L. Sierrasesúmaga \\ From the Laboratory of Pediatrics, University of Navarra, Pamplona, Spain.
}

Address reprint requests to: A. Patiño García, Laboratory of Pediatrics, University of Navarra, Irunlarrea $\mathrm{s} / \mathrm{n}^{\circ}, \mathrm{E}-31080$ Pamplona, Spain.

\begin{abstract}
Recent data suggest that deletion of p16INK4 and mutation of TP53 are among the most common genetic events in the development of human cancer, since the codified proteins act as brakes of the abnormal cell cycle. As the molecular events leading to the development of pediatric bone sarcomas remain unclear, we analyzed 75 osteosarcoma and Ewing sarcoma samples from 43 pediatric patients to search for alterations at the TP53 or p16INK4 tumor suppressor genes. By means of PCRDGGE (polymerase chain reaction and denaturing gradient gel electrophoresis) we detected TP53 point mutations in $18.6 \%$ of the tumor samples, but no constitutional mutations. In the analysis of p16INK $4,7 \%$ of the samples harbored deletions of the gene but no point mutations were detected by SSCP (single strand conformation polymorphism) analysis, just the polymorphism Ala $\rightarrow$ Thr at codon 148 . These data support the hypothesis that TP53 alterations may play a role in the development of pediatric bone tumors and that the primary mechanism of inactivation of p16INK4 seems to be homozygous deletion rather than point mutation.
\end{abstract}

\section{INTRODUCTION}

The molecular events leading to the development of pediatric bone tumors remain unclear and, to date, the oncogenes or tumor suppressor genes responsible have not been reported. Nevertheless, genetic alterations which affect normal function of RB-1 and TP53 tumor suppressor genes have been demonstrated in these types of tumors [13], although other genetic events critical for tumorigenesis have not yet been well defined.

Recently, it has been reported that deletion of the p16INK4 gene is common in various human tumors [4], and the encoded protein has been identified as a regulatory product in the cell cycle. p16INK4 inhibits the CDK4-cyclin D complexes, preventing the phosphorylation of regulatory proteins which block G1 to $\mathrm{S}$ transition and cell growth [5]. 
Homozygous deletions and mutations at the p16INK4 locus (9p21) have been demonstrated in a wide variety of tumor-derived cell lines, although the overall incidence of alterations is less in primary tumors than in cell lines [6]. This fact may represent an "in vitro" artifact or suggest the presence of another nearby tumor suppressor gene. In a previous study, point mutations affecting p16INK4 were detected in several sarcoma cell lines, but not in cell fines derived from osteosarcoma, in which only homozygous deletions were reported, suggesting that alterations may originate by different mechanisms, depending on the tissue type [7]. In addition, little data concerning primary pediatric bone tumors has been published so far, and it is unclear to what extent alterations in the p16INK4 gene are relevant to their development.

Mutations affecting the TP53 tumor suppressor gene at $17 \mathrm{p}$ are the most common genetic alterations yet identified in sporadic human tumors [8]. This gene acts as a transcriptional activator and plays a key role in suppressing abnormal cell proliferation by acting as a G1 cell cycle checkpoint for DNA damage [9-10].

In the present study, we examined alterations of p16INK4 and TP53 genes in osteosarcomas and Ewing sarcomas in which absence of point mutations at codons 12 and 61 of the RAS-family genes had already been demonstrated [11], in order to determine if, and to which extent, these genes are involved in carcinogenesis in this subset of pediatric bone tumors.

\section{MATERIALS AND METHODS}

\section{Patients and Samples}

Primary tumors and peripheral blood samples were obtained from patients treated at the Clínica Universitaria in Pamplona, Spain. 75 samples from 43 patients were examined: 38 osteosarcomas and five Ewing sarcomas. Matched normal DNA was available for 11 of these patients. In addition, we analyzed 20 peripheral blood samples from bone sarcoma patients for whom tissue samples were not available in order to test the possibility that they harbor constitutional alterations.

Genomic DNA was obtained by isolation and purification with proteinase $\mathrm{K}$ and extraction using conventional phenol-chloroform procedures in the case of peripheral lymphocytes $(n=31)$ and fresh tissues $(n=15)$. Serial cuts were obtained from paraffin-embedded samples $(n=49)$ and they were deparaffinized following conventional procedures with slight modifications [12].

\section{P16INK4 Analysis}

PCR and SSCP. Exons 1 and 2 of the p16INK4 gene were amplified using primers and under conditions described elsewhere [13]. In brief, $200 \mathrm{ng}$ of genomic DNA was amplified in a $25 \mu \mathrm{l}$ PCR reaction containing 10 pmol of each primer, $200 \mu \mathrm{M}$ dNTPs, $20 \mathrm{mM}$ Tris-HCl ( $\mathrm{pH} 8.5), 16 \mathrm{mM} \mathrm{SO}{ }_{4}\left(\mathrm{NH}_{4}\right)_{2}, 2.5 \mathrm{mM} \mathrm{MgCl} 2,150 \mu \mathrm{g} / \mathrm{ml} \mathrm{BSA}, 5 \%$ DMSO, and 1 unit of Taq DNA polymerase (BioTaq ${ }^{\mathrm{TM}}$, Bio-probe Systems). 
SSCP analysis was performed on a $12 \%$ polyacrylamide gel (49:1 acrylamide: bisacrylamide) containing 10\% glycerol. Before electrophoresis, $2 \mu 1$ sample was added to $10 \mu \mathrm{l}$ stop solution ( $95 \%$ formamide, $20 \mathrm{mM}$ EDTA, $0.05 \%$ bromophenol blue, and $0.05 \%$ xylene cyanol), heated to $95^{\circ} \mathrm{C}$ for 6 minutes and immediately placed on ice. Electrophoresis in a $4^{\circ} \mathrm{C}$ chamber was maintained at 200 volts until the xylene cyanol reached the bottom of the gel. After electrophoresis, bands were visualized by silver staining as described by Hiort [14].

When necessary, SSCP analysis was repeated after digestion of the PCR fragments with the restriction enzyme SmaI.

Recognition of the A148T polymorphism at exon 2 of the p16INK4 gene was by failure to digest with SacII.

\section{P16INK4 Deletion Analysis}

To investigate the presence of homozygous deletion for the p16INK4 gene, we coamplified p16INK4 exon 2 with a $220 \mathrm{bp}$ fragment of the V $\delta 2$ region of the TCR (Tcell receptor) gene as control for amplification. The PCR reaction was similar to those conditions described above.

For visualization, PCR fragments were separated by electrophoresis on a $2 \%$ agarose gel containing $0.5 \mu \mathrm{g} / \mu \mathrm{l}$ ethidium bromide and photographed under UV light. To enable comparison of both PCR products, the PCR reaction was maintained within the exponential range of amplification, minimizing the amount of starting DNA and the cycle number.

Homozygous deletion results were interpreted if there was complete absence of the amplification signal of the p16INK4 exon 2 fragment in three separate reactions.

\section{TP53 Mutation Analysis and DNA Sequencing}

Screening for mutations at the TP53 gene was performed as previously described [15, $16]$ with slight differences in running times.

Bands with altered electrophoretic mobilities were sequenced by cycle sequencing using the Thermo Sequenase ${ }^{\mathrm{TM}}$ Cycle Sequencing kit (Amersham Life Science).

\section{RESULTS}

\section{Screening for TP53 Mutations}

We analyzed exons 5 through 8 of the TP53 tumor suppressor gene because this region accounts for about $80 \%$ of the conserved domains of the gene, and is the location of more than $95 \%$ of the mutations reported in sporadic tumors. 
We detected alterations in 10 samples corresponding to eight patients: seven osteosarcomas and one Ewing sarcoma (Figs. 1 and 2). The locations of the mutations were as follows: four in exon 8, two in exon 5, and one in exons 6 and 7 respectively (Table 1). We detected alterations in $18.6 \%$ of the patients, which confirms previous reports indicating an important role for the TP53 gene in carcinogenesis. It is noteworthy that alterations were found to be present in primary $(43 \mathrm{~B}, 45 \mathrm{~A}, 46 \mathrm{~B}, 22 \mathrm{C})$, recurrent (45B), and metastasic (2C, 15C, 19R, 45C, 80R) samples.

\section{Screening for p16INK4 Deletions}

Homozygous deletions of p16INK4 were detected in five samples belonging to three patients (Fig. 3). This suggests an overall frequency for homozygous deletion of $7 \%$, not substantially different from that reported for adult primary tumors [17]. Al) three patients had osteosarcomas at stage IIB, according to the Enneking classification [18].

In the case of one of the osteosarcoma patients, samples from the primary tumor and from two different metastases were available, and we detected homozygous deletions in all of them.

\section{Screening for p16INK4 Point Mutations}

The SSCP analysis of exons 1 and 2 of the gene identified four samples with identical altered SSCP pattern for exon 2 compared to controls carrying known mutations. Digestion with SacII revealed the polymorphism A148T that was present in our series with a frequency of $3.2 \%$ (Fig. 4 ).

We found no mutations affecting the coding region of exons 1 or 2 of the p16INK 4 gene in our tumors or blood samples.

\section{DISCUSSION}

Clinical follow-up data from diagnosis to present was available for all bone sarcoma patients in this study, and covers development of metastases, treatment, disease-free survival time, and total survival time.

Our study of 43 pediatric patients with bone sarcomas revealed alterations of the p16INK4 tumor suppressor gene in 7\% of the samples, and point mutations of TP53 in $18.6 \%$. These values are both in agreement with those previously reported, and support the hypothesis that the main mechanism of inactivation of the p16INK4 gene in primary tumors is homozygous deletion. They also support the idea that TP53 alterations may play a role in the development of pediatric, as well as adult, osteosarcoma.

Missense mutations in the evolutionarily conserved codons of the TP53 gene (codons 118 to 280) are commonly implicated in the development of human cancer. In our series, $75 \%$ of mutant samples were found to carry such mutations. 
All TP53 mutations we found have already been reported in the literature [19]; some of them-such as the Arg to His change at codon 273 and the generation of the stop codon at position 196 - have been described in a wide variety of tumors and cell lines, while the missense mutation at codon 268 and the frameshift and tandem mutation at exon 7 have only been reported, to our knowledge, in two cases each, and never occurring in the same patient.

It was not possible to obtain DNA of sufficient quality for sequencing from one tumor sample (2C, Table 1), and therefore we do not know the nature and position of this alteration affecting the exon 5 of the gene. The possibility that the nucleotide alteration present in the tumor does not change the encoded aminoacid or changes it unto a synonymous one cannot be excluded; this would therefore represent a genetic polymorphism with no clinical implication. The PCR amplification fragment corresponding to the sample migrated more slowly in the DGGE gel than the control fragment, and it would therefore be predicted to have suffered a GC to AT change.

It may well be that another gene or genes involved in the TP53 regulatory pathway are altered in these tumors.

A good candidate is the MDM2 (murine double minute-2) gene which encodes a protein that may interact with p53 protein, inhibiting TP53 mediated transactivation. These two proteins, MDM2 and p53, are parts of an autoregulatory loop in which the MDM2 mRNA transcription is enhanced by p53 overexpression. In previous reports $[20,21]$ it has been demonstrated that between $15 \%$ and $30 \%$ of human osteosarcomas and soft tissue sarcomas present MDM2 amplification and that none of the tumors with MDM2 amplification had mutated TP53; therefore, amplification of MDM2 may provide an alternative mechanism for TP53 inactivation.

In our deletion analysis of p16INK4, we considered homozygous deletions in those patient samples in which complete absence of the amplification fragment of the exon 2 of the gene was demonstrated. Nevertheless, our frequency of homozygous deletions may be an underestimate of the real number because some hemizygously and even homozygously deleted samples may appear as non-deleted due to the amplification of the one allele present or even to amplification of normal p16INK4 alleles present in spurious normal cells in the tumor samples.

The absence of mutations in the p16INK4 gene in our series is not a surprising fact, given the low frequency of such alterations detected in adult osteosarcoma patients [17]. Alternatively, it may be that the SSCP technique which we used for the screening failed to detect the alterations, given that the amplification size (350 bp for exon 1 and $347 \mathrm{bp}$ for exon 2) is at the upper limit of what the technique can discriminate [22]. In view of this possibility, we also digested the amplification products of exons 1 and 2 with the restriction enzyme SmaI, thus obtaining ideal fragments for analysis by SSCP.

We also tried to analyze fragments by DGGE, which can detect $100 \%$ of the alterations in a given DNA fragment [23]. Despite achieving very good melting profiles for exons 1 and 2 of the p16INK4 gene, the high GC content of the fragments raised the melting temperature over the limits of resolution for conventional DGGE gels. 
In the SSCP analysis of exon 2 of the p16INK4 gene, we found four samples from two patients that showed identical SSCP banding patterns clearly different from those of the normal controls. The fact that two of the four samples were DNAs extracted from peripheral blood led to the suspicion that these alterations may be accounted for by a polymorphism. Failure to digest with SacII and the size of the resulting fragments indicated the presence of the polymorphism A148T; this base change $(G \rightarrow A)$ abolishes the SacII restriction site and changes codon 148 from alanine to threonine. The frequency of this polimorphism in our series was 3.2\%, lower than that reported by Sun et al. [13] for white Caucasians. The difference is significant and may reflect differences in populations, as has been demonstrated with Alaskan individuals.

In our series, we found that the three patients with a deleted p16INK4 gene were diagnosed as having chondroblastic osteosarcoma, and all developed lung metastases and died within a period of between 16 and 34 months. This suggests that deletion of p16INK4 may be valuable as a prognostic factor associated with tumors of more aggressive behavior, although this series is too small to draw definitive clinical conclusions.

It has been demonstrated that there seems to exist an inverse correlation between the present of the p16INK4 encoded protein and that of the RB1 gene $\left(\mathrm{p} 110^{\mathrm{RB}}\right)$. The explanation for this fact is that the suppressive potential of $\mathrm{p} 110^{\mathrm{RB}}$ is inactivated by phosphorylation, which can be inhibited by p16INK4 binding to the corresponding CDK [24]. Therefore, loss or alteration of p16INK4 expression would affect the functions of $\mathrm{p} 110^{\mathrm{RB}}$. Thus, it seems that loss of p16INK4 and loss of RB may have similar effects on cell cycle progression and that they are part of the same pathway in tumorigenesis; this has a special meaning in bone sarcomas, in which RB1 mutations have been demonstrated to happen non-randomly $[2,3]$.

Lung metastasis developed in half of the patients whose primary tumors harbored mutations at the TP53 gene, but four osteosarcoma patients showed no evidence of disease during the time following their initial treatment, although TP53 mutations were identified in their samples. Therefore, no definite association was observed between TP53 mutation and the incidence of metastases. We did not find association with any other clinical parameters, such as tumor grading or histologic subtypes, either; although in previous reports [25-27] it has been suggested that the presence of an altered TP53 gene may be related to more aggressive or invasive tumors.

\section{ACKNOWLEDGEMENTS}

We are greatly indebted to Dr. R. Hamelin, Dr. X. Zhou, and Dr. S. Zhang for providing us with mutant DNA samples, and to Fundación Echébano for financial support. We would also like to thank the Department of Traumatology and Surgery of the Clínica Universitaria at Pamplona, Spain for providing us with some of the patient samples. 


\section{REFERENCES}

1) Toguchida, J, Yamaguchi T, Ritchie B, Beauchamp RL, Dayton SH, Herrera GE, Yamamuro T, Kotoura Y, Sasaki MS, Little JB (1992): Mutation spectrum of the p53 gene in bone and soft tissue sarcomas. Cancer Res 52:6194-6199.

2) Friend SH, Bernards R, Rogelj S, Weinberg RA, Rapaport JM, Albert DM, Dryja TP (1986): A human DNA segment with properties of the gene that predisposes to retinoblastoma and osteosarcoma. Nature 323:643-646.

3) Wadayama B, Toguchida J, Shimizu T, Ishizaki K, Sasaki MS, Kotoura Y, Yamamuro T (1994): Mutation spectrum of the retinoblastoma gene in osteosarcomas. Cancer Res 54:30423048.

4) Kamb A, Gruis NA, Weaver-Feldhaus J, Liu Q, Harshman K, Tavtigian SV, Stockert E, Day III RS, Johnson BE, Skolnick MH (1994): A cell cycle regulator potentially involved in genesis of many tumor types. Science 264:436-440.

5) Serrano M, Hannon GJ, Beach D (1993): A new regulatory motif in cell-cycle control causing specific inhibition of cyclin D/CDK4. Nature 366:704-707.

6) Spruck CH, Gonzalez Zulueta M, Shibata A, Simoneau AR, Liu MF, Gonzales F, Tsai YC, Jones PA (1994): p16 gene in uncultured tumors. Nature 370:183-184.

7) Liu Q, Neuhausen S, McClure M, Frye C, Weaver-Feldhaus J, Gruis NA, Eddington K, Allalunis-Turner MJ, Skolnick MH, Fujimura FK, Kamb A (1995): CDKN2 (MTS1) tumor suppressor gene mutations in human tumor cell lines. Oncogene 10:1061-1067.

8) Nigro JM, Baker SJ, Preisinger AC, Jessup JM, Hostetter R, Cleary K, Bigner SH, Davidson N, Baylin S, Devilee P, Glover T, Collins FS, Weston A, Modali R, Harris CC, Vogelstein B (1989): Mutations in the p53 occur in diverse human tumor types. Nature 342:705-708.

9) Kastan MB, Onyekwere O, Sidransky D, Vogelstein B, Craig RW (1991): Participation of p53 protein in the cellular response to DNA damage. Cancer Res 51:6304-6311.

10) O'Rourke RW, Miller CW, Kato GJ, Simon KJ, Chen D-L, Dang C-V, Koeffler PK (1990): A potential transcriptional activation element in the p53 protein. Oncogene 5:1829-1832.

11) Antillón-Klüssmann $F$, García-Delgado $M$, Villa-Elízaga I, Sierrasesúmaga L (1995): Mutational activation of ras genes is absent in pediatric osteosarcoma. Cancer Genet Cytogenet 79:49-53.

12) Rogers BB, Alpert LC, Hine EA, Buffone GJ (1990): Analysis of DNA in fresh and fixed tissue by polymerase chain reaction. Am J Pathol 136:541-548.

13) Sun Y, Hildesheim A, Lanier AEP, Cao Y, Yao K-T, Raab-Traub N, Yang C-S (1995): No point mutation but decreased expression of the p16/MTS1 tumor suppressor gene in nasopharyngeal carcinomas. Oncogene 10:785-788.

14) Hiort O, Wodtke A, Struve D, Zöllner A, Sinnecker GHG, German "Collaborative Intersex Study Group" (1994): Detection of point mutations in the androgen receptor gene using non-isotopic single strand conformation polymorphism analysis. Hum Mol Genet 3:1163-1166.

15) Hamelin R, Jego N, Laurent-Puig R, Vidaud M, Thomas G (1993): Efficient screening of p53 mutations by denaturing gradient gel electrophoresis in colorectal tumors. Oncogene 8:2213-2220. 
16) Borresen A-L, Hovig E, Smith-Sorensen B, Malkin D, Lystad S, Andersen TI, Nesland JM, Isselbacher KJ, Friend SH (1991): Constant denaturing gel electrophoresis as a rapid screening technique for p53 mutations. Proc Natl Acad Sci USA 88:8405-8409.

17) Miller CW, Aslo A, Campbell MJ, Kawamata N, Lampkin BC, Koeffler HP (1996): Alterations of the p15, p16 and p18 genes in osteosarcoma. Cancer Genet Cytogenet 86:136-142.

18) Enneking WF, Spanier SS, Goodman MA (1980): A system for the surgical staging of musculoskeletal sarcoma. Clin Orthop 153:106-120.

19) Hollstein M, Rice K, Greenblatt MS, Soussi T, Fuchs R, Sorlie T, Hovig E, Smith-Sorensen B, Montesano R, Harris CC (1994): Database of p53 gene somatic mutations in human tumors and cell lines. Nucleic Acids Res 22:3551-3355.

20) Oliner JD, Kinzier KW, Meltzer PS, George DL, Volgestein B (1992): Amplification of a gene encoding a p53-associated protein in human sarcomas. Nature 358:80-83.

21) Ladayi M, Cha C, Lewis R, Jhanwar SC, Huvos AG, Healey JH (1993): MDM2 gene amplification in metastatic osteosarcoma. Cancer Res 53:16-18.

22) Sheffield VC, Beck JS, Kwitek AE, Sandstrom DW, Stone EM (1993): The sensitivity of single strand conformation polymorphism analysis for the detection of single base substitutions. Genomics 16:325-332.

23) Lerman L, Silverstein K (1987): Computational simulation of DNA melting and its application to denaturing gradient gel electrophoresis. Methods Enzymol 155:482-501.

24) Lukas J, Parry D, Aagaard L, Mann DJ, Bartkova J, Strauss M, Peters G, Bartek J (1995): Retinoblastoma-protein dependent cell-cycle inhibition by the tumor suppressor p16. Nature 375:503-506.

25) Fults D, Brockmeyer D, Tullons MW, Pedone CA, Cawthon RM (1992): p53 mutation and loss of heterozygosity on chromosome 17 and 10 during human astrocitoma progression. Cancer Res 52:674-679.

26) Mazars R, Spinardi L, Beucheikh M, Simony-Lafontaine J, Jeanteur P, Theillet C (1992): p53 mutations occur in aggressive breast cancer. Cancer Res 52:3918-3923.

27) Fujimoto T, Yamada Y, Okajima E, Kakizoe T, Sasaki H, Sigumura T, Terada M (1992): Frequent association of p53 gene mutation in invasive bladder cancer. Cancer Res:393-398. 
Table 1. TP53 mutations found in the DGGE analysis of the tumor samples

\begin{tabular}{|c|c|c|c|c|c|}
\hline $\begin{array}{c}\text { Sample } \\
\mathbf{N}^{\circ}\end{array}$ & Exon & Codon & DNA change & Protein change & Tumor \\
\hline $22 \mathrm{C}$ & 8 & 273 & $\mathrm{CGT} \rightarrow \mathrm{CAT}$ & Arg $\rightarrow$ His & Osteosarcoma $(0)^{1}$ \\
\hline $80 \mathrm{R}$ & 8 & 273 & $\mathrm{CGT} \rightarrow \mathrm{CAT}$ & Arg $\rightarrow$ His & Ewing Sarcoma \\
\hline $45 \mathrm{~A}, \mathrm{~B}, \mathrm{C}$ & 8 & 273 & $\mathrm{CGT} \rightarrow \mathrm{CAT}$ & Arg $\rightarrow$ His & Osteosarcoma $(\mathrm{C})^{2}$ \\
\hline $43 \mathrm{~B}$ & 8 & 268 & $\mathrm{AAC} \rightarrow \mathrm{AGC}$ & Asn $\rightarrow$ Ser & Osteosarcoma (O) \\
\hline \multirow[t]{2}{*}{$19 \mathrm{R}$} & 7 & 250 & delC & Frameshift & Osteosarcoma (C) \\
\hline & & $250-251$ & $\mathrm{CCC} \rightarrow \mathrm{TTC}$ & Pro $\rightarrow$ Phe & (same) \\
\hline $46 \mathrm{~B}$ & 6 & 196 & $\mathrm{CGA} \rightarrow \mathrm{TGA}$ & Arg $\rightarrow$ Stop & Osteosarcoma $(\mathrm{F})^{3}$ \\
\hline $15 \mathrm{C}$ & 5 & 175 & $\mathrm{CGC} \rightarrow \mathrm{CAC}$ & Arg $\rightarrow$ His & Osteosarcoma (O) \\
\hline $2 \mathrm{C}$ & 5 & $?$ & $?$ & $?$ & Osteosarcoma (O) \\
\hline \multicolumn{6}{|c|}{$\begin{array}{l}{ }^{1} \text { Osteoblastic subtype. } \\
{ }^{2} \text { Chondroblastic subtype. } \\
{ }^{3} \text { Fibroblastic subtype. }\end{array}$} \\
\hline
\end{tabular}




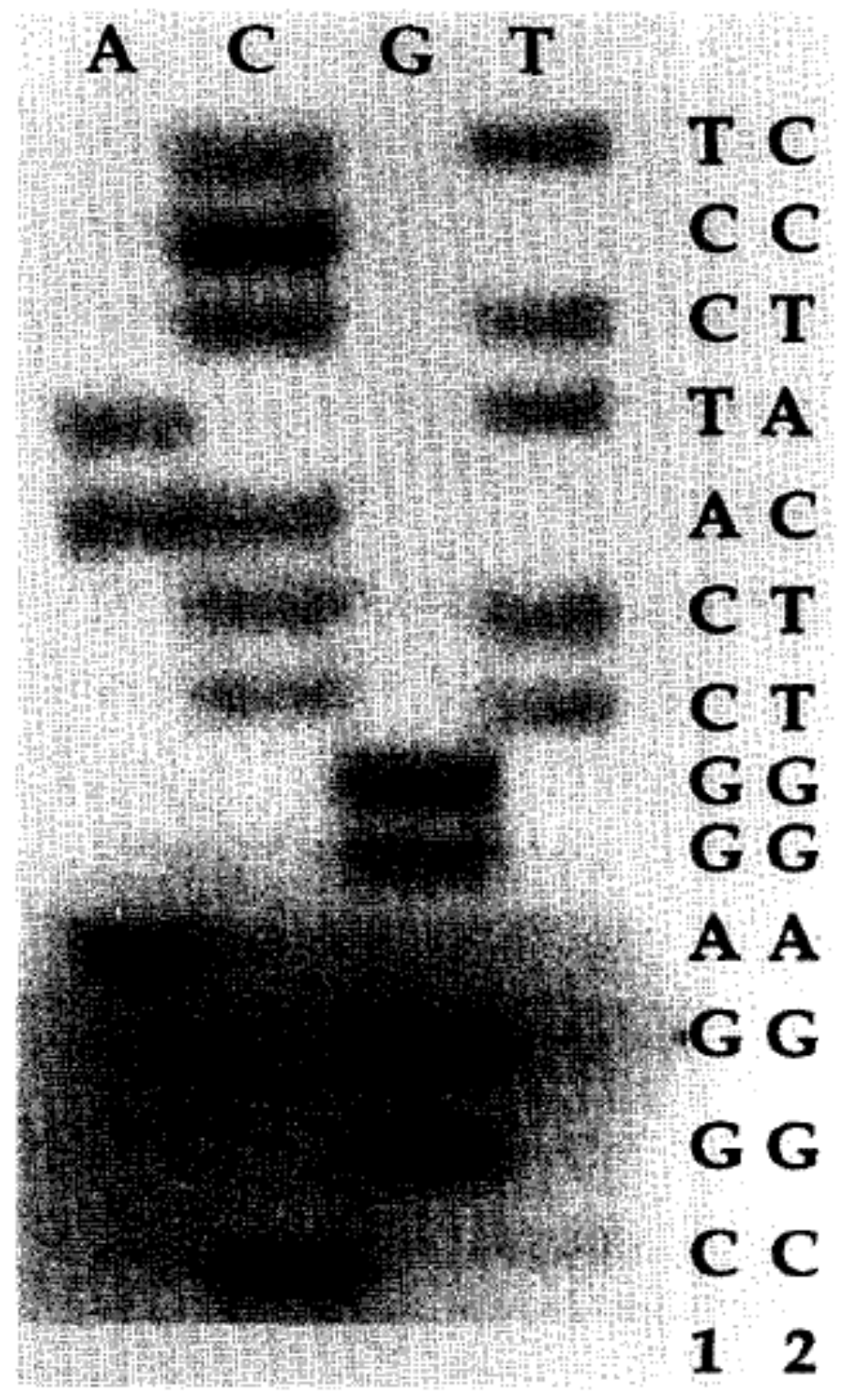

Figure 1. Direct genomic sequence analysis of the PCR amplification of the TP53 exon 7 of patient 19R showing deletion of a C in allele 1 and the CCC to TTC tandem change in the non-deleted allele (allele 2). 


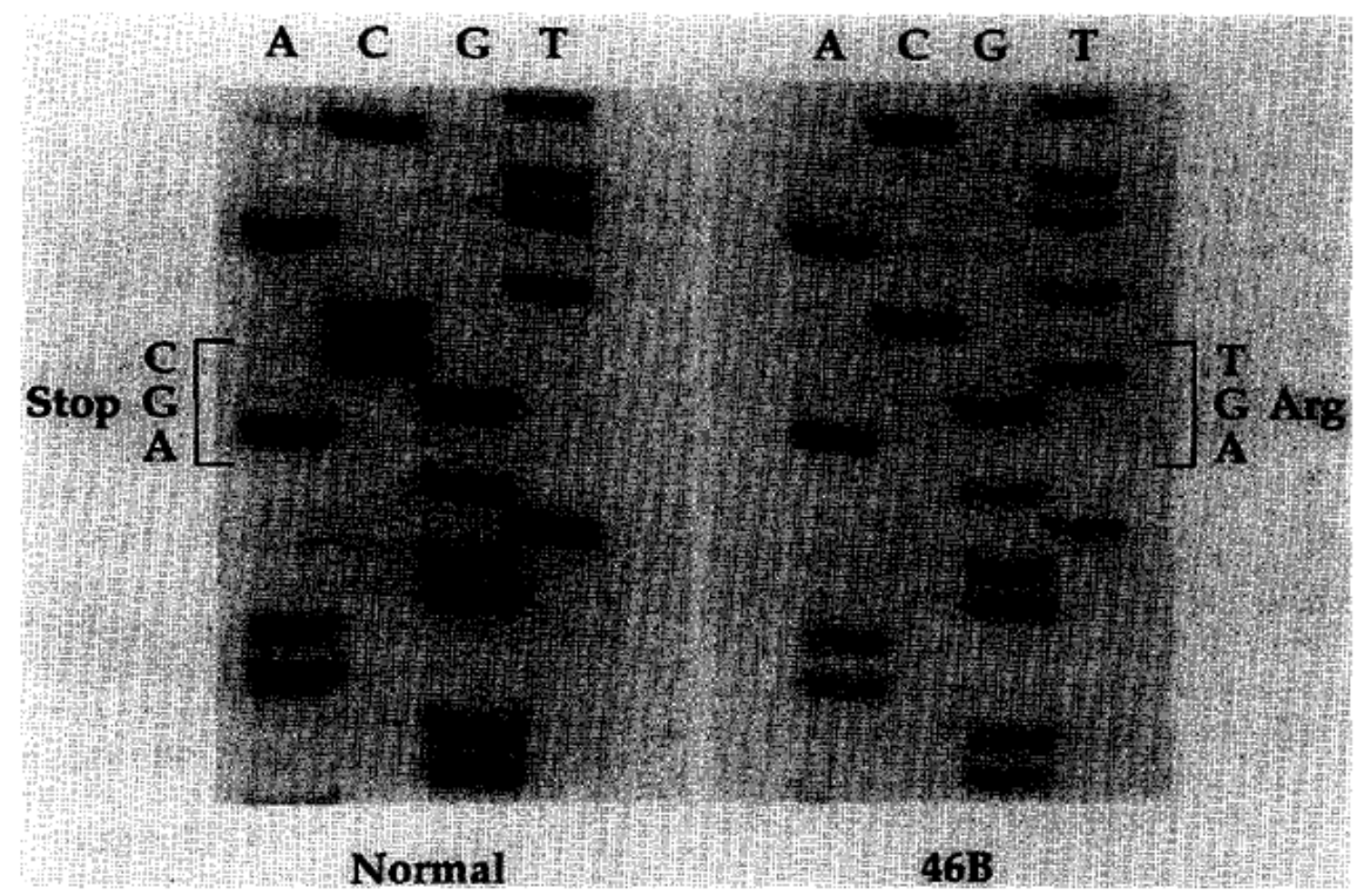

Figure 2. Partial sequence of TP53 exon 6 of patient 46B versus a normal control, showing a CGA to TGA change that changes the wild type arginine codon into a stop codon.

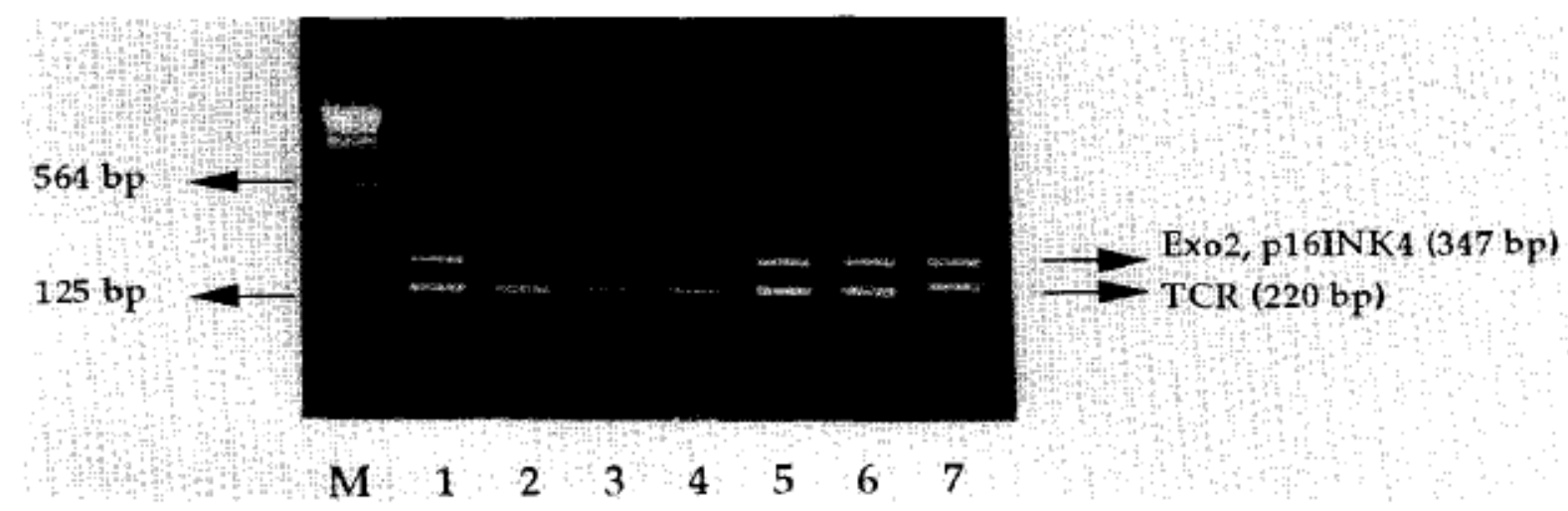

Figure 3. Coamplification of the p16INK4 exon 2 and the TCR fragment showing absence of amplification of the fragment corresponding to p16INK4 in lanes 2, 3, and 4. $\mathrm{M}=$ molecular weight marker, and lanes 1, 5, 6, and 7 are non-deleted samples. 


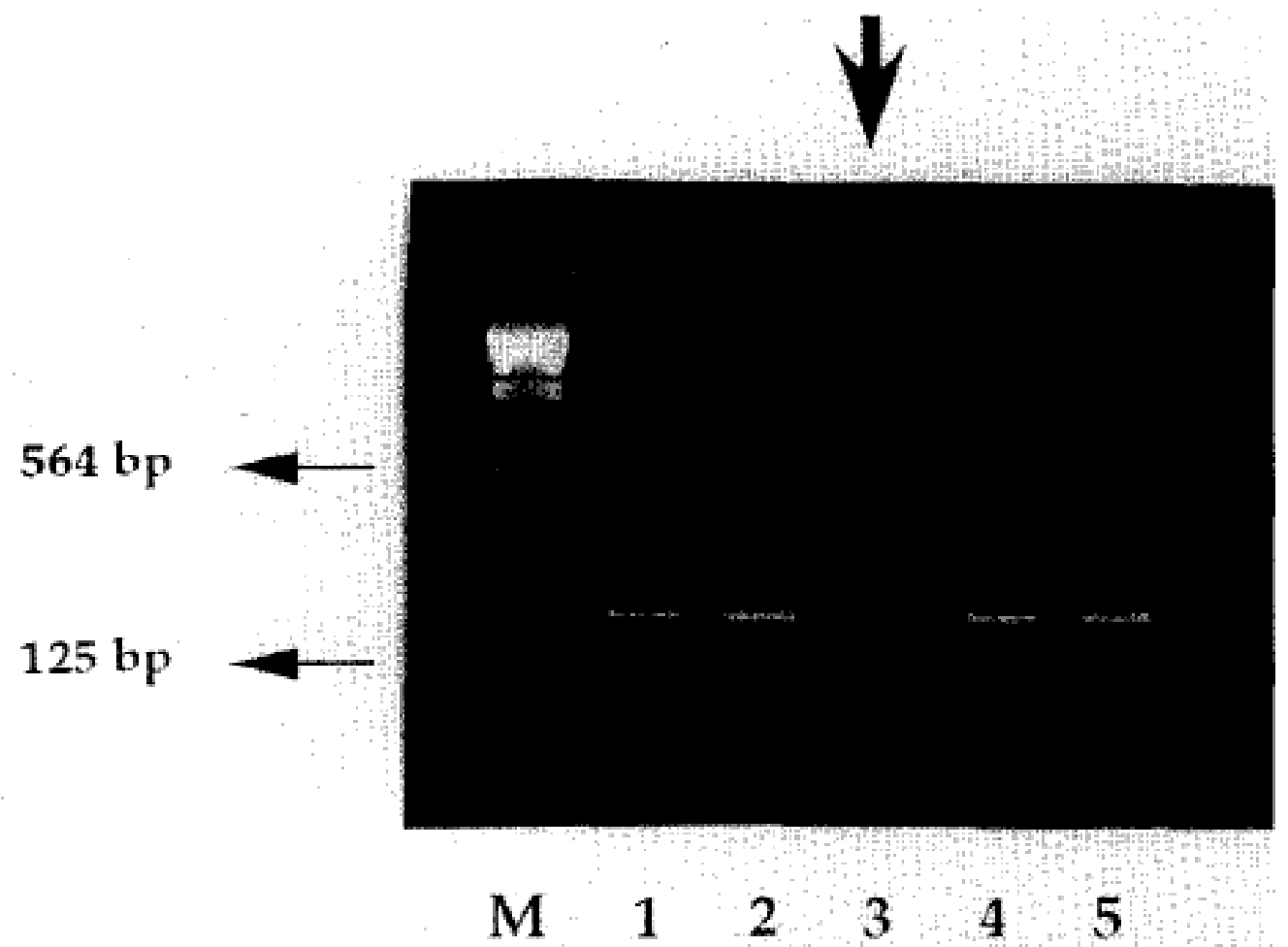

Figure 4. SacII digestion of the amplification of p16INK4 exon 2, showing a nondigested allele in one tumor sample carrying the polymorphism A148T (lane with an arrow). 